\title{
Surgery for Craniovertebral Junction Pathologies: Minimally Invasive Anterior Submandibular Retropharyngeal Key-Hole Approach
}

\section{Árpád Viola ( $\sim$ arpadviola@gmail.com )}

Péterfy Hospital - Manninger Jenő National Traumatology Institution

István Kozma

Péterfy Hospital - Manninger Jenő National Traumatology Institution

Dávid Süvegh

Semmelweis Egyetem

\section{Technical advance}

Keywords: odontoidectomy, minimally invasive, key-hole approach, submandibular retropharyngeal, ventral decompression, patient safety

Posted Date: November 24th, 2020

DOI: https://doi.org/10.21203/rs.3.rs-112566/v1

License: (9) This work is licensed under a Creative Commons Attribution 4.0 International License. Read Full License

Version of Record: A version of this preprint was published at BMC Surgery on April 19th, 2021. See the published version at https://doi.org/10.1186/s12893-021-01198-z. 


\section{Abstract}

\section{Background}

Our objective was to develop a new, minimally invasive surgical technique for the resolution of craniovertebral junction pathologies, which can eliminate the complications of the previous methods, like liquor-leakage, velopharyngeal insufficiency and wound-dehiscence associated with the transoral or lateral approaches.

\section{Methods}

During the first stage of the operation, three patients underwent occipito-cervical dorsal fusion, while the fourth patient received C1-C2 fusion according to Harms. C1-C2 decompressive laminectomy was performed in all four cases. Ventral C1-C2 decompression with microscope assisted minimally invasive anterior submandibular retropharyngeal key-hole approach (MIS ASR) method was performed in the second stage. The MIS ASR similarly to the traditional anterior retropharyngeal surgery - preserves the hard and soft palates, yet can be performed through a $25 \mathrm{~mm}$ wide incision with the use of only one retractor.

\section{Results}

The MIS ASR approach was a success in all four cases, there were no intra- and postoperative complications. This method, compared to the transoral approach, provided on average $23 \%\left(4.56 \mathrm{~cm}^{2} /\right.$ $6.05 \mathrm{~cm}^{2}$ ) smaller dural decompression area; nonetheless, the entire pathology could be removed in all cases. After the surgery, all patients have shown significant neurological improvement.

\section{Conclusion}

Based on the outcome of these four cases we think that the MIS ASR approach is a safe alternative to the traditional methods while improving patient safety by reducing the risks of complications.

\section{Background}

Odontoidectomy serves as the resolution of ventral compression of the upper cervical medulla. It can be performed via traditional transoral, endoscopic endonasal, anterior transcervical retropharyngeal, or with a lateral approach. The most common method for ventral decompression is by transoral transpharyngeal (TO) odontoidectomy [1] with the option to add a transmandibular route or Le Fort osteotomy for increased visualization and surgical bed [2]. The benefit of endoscopic endonasal (EE) odontoidectomy over the transoral method is that the preservation of the hard and soft palates drastically decreases the risk of velopharyngeal insufficiency, while a straight approach to the odontoid process is still provided [35]. The risks and limitations of transmucosal surgeries can be avoided with an anterior-transcervicalretropharyngeal approach. Using the standard Smith-Robinson method, access to the C3 vertebra and disc is not always attainable, while the anterior retropharyngeal (AR) approach provides access to the 
whole cervical spine [6, 7]. Although lateral routes provide wider access, the risks of injuries to the vertebral artery, jugular bulb and hypoglossal nerve are higher [8-11]. Our objective is to introduce a surgical method that we have used for C1-C2 ventral decompression, the microscope assisted minimally invasive anterior submandibular retropharyngeal key-hole approach (MIS ASR), which - similarly to the traditional anterior retropharyngeal surgery - preserves the hard and soft palates, yet can be performed through a $25 \mathrm{~mm}$ wide incision with the use of only one retractor. We performed this minimally invasive procedure on four patients in a one-year period from June 2019 to May 2020. Indications included three cases of ventral C1-C2 stenosis, caused by rheumatoid arthritis in two cases, in one case caused by metastases of a cervix squamous-cell carcinoma, and in the fourth case due to medulla oblongata compression caused by the dislocated traumatic fracture of the $\mathrm{C} 2$ vertebra's odontoid process.

\section{Methods}

The development of the MIS ASR procedure was inspired by a trauma case. A cortical bone fragment broke off from the odontoid process of the $\mathrm{C} 2$ vertebra and compressed the spinal cord on the left side [12]. We chose the ASR, because the MRI confirmed a ventral dura injury, which along with the high risk of velopharyngeal insufficiency occurring with the transoral approach, would have increased the risk of wound dehiscence and sepsis. With the submandibular "key-hole" approach, besides using fibrin glue, we could also tamponade the dural injury with multiple layers of vital soft tissue. During the surgery and in the postoperative period, no cerebrospinal fluid (CSF) leakage or other complications presented. After this successful operation on the trauma patient, we began to utilize the MIS ASR key-hole method to assess its feasibility in rheumatoid arthritis and tumorous cases, the two most common reasons for ventral compression. The surgery was performed on an 83 and a 62-year-old male patients with ventral spinal stenosis caused by rheumatoid arthritis, on a 42-year-old female to whom the ventral spinal stenosis was due to a metastasis of a cervix squamous-cell carcinoma, and on the 43-year-old male with the traumatic odontoid fracture with dislocation resulting in the compression of the medulla oblongata. During the first stage of the operation, three patients underwent occipito-cervical dorsal fusion, while the fourth patient received C1-C2 fusion according to Harms. C1-C2 decompressive laminectomy was performed in all four cases. Ventral C1-C2 decompression was performed in the second stage. An additional movie shows the surgery in details (Additional file 1). All patients were supine, stabilized in Mayfield headrest. During the MIS ASR approach, we began with a $25 \mathrm{~mm}$ wide ventral and submandibular incision, 30-40 $\mathrm{mm}$ below the mental protuberance, beginning from the right side and extending $5 \mathrm{~mm}$ left towards the midline (Fig. 1.). The platysma muscle was incised crosswise with a $25 \mathrm{~mm}$ wide incision, then access to the spine was achieved by blunt dissection of the mylohyoid muscle, corresponding to its fibers, while retracting the anterior belly of the right digastric muscle laterally. We mobilized the upper portion of the oropharynx cranio-medially to reach the corpus of the $\mathrm{C} 2$ vertebra and odontoid process as well as the $\mathrm{C} 1$ anterior tubercle and arch. In order to elevate the upper part of the oropharynx, we used one $15 \mathrm{~mm}$ wide - $80 \mathrm{~mm}$ long carbon retractor (DePuy Synthes Synframe). According to the different stages of the surgery, the suction, bipolar diathermy, micro drill and Kerrison Rongeur were positioned in the surgeon's left and right hand in order to provide adequate retraction of the lateral and medial soft tissue (Fig. 2). In 
each patient, the anterior tubercle of the $\mathrm{C} 1$ vertebra was $105,98,95,78 \mathrm{~mm}$ deep, while the ventral base of the $\mathrm{C} 2$ was $91,79,74,70 \mathrm{~mm}$ respectively. After the removal of bone and soft tissue, the dura mater was $128,110,102,101 \mathrm{~mm}$ deep from the incision (Table 1). Using this microscope assisted minimally invasive anterior submandibular retropharyngeal key-hole (MIS ASR) approach, C1-C2 ventral decompression and freeing up of the dura mater can be performed. Operative time in the four cases were $165,150,135$ and 130 minutes respectively -145 minutes on average, and the blood loss was between $80-120 \mathrm{ml}$.

In all four cases, we also prepared a surgical plan for the transoral approach (Table 1).

\section{Results}

\section{Patient one:}

We admitted an 83-year-old male from a neurological department, with 2-month persistent symptoms and slowly developing paraparesis. The MRI identified a rheumatoid pannus causing ventral compression at the C1-2 level. Two days after the posterior C1-2 fixation and laminectomy, we performed the ASR surgery without any complications. After the procedure, the patient's paraparesis gradually resolved itself and he became self-sufficient.

\section{Patient two:}

The 62-year-old male presented with moderate tetraparesis, dysphagia, and Bechterew disease in the anamnesis. From the MRI scans we identified a rheumatoid pannus compressing the medulla oblongata. Nine days after the dorsal C1-2 fusion we performed the ASR surgery, during which the anterior arch of the $\mathrm{C} 1$, the upper two-thirds of the odontoid process, and the pannus causing the compression were removed. This surgery was completed without complications. The neurological deficit, dysphagia and tetraparesis gradually resolved themselves, and 10 days after the second surgery the patient was discharged to his home.

\section{Patient three:}

With the 42-year-old female, the CT and contrast MRI showed the $\mathrm{C} 1$ and $\mathrm{C} 2$ vertebra's tumorous infiltration - due to a metastatic cervix squamous cell carcinoma metastasis - which caused the ventral compression of the spinal cord. She had no neurological deficits, only pain in her nape which radiated to the left shoulder. Two days after the occipitocervical - C0-3 dorsal stabilization, we performed the ASR surgery to remove the metastasis and free up the spinal cord. On the fourth day after the second surgery she was discharged to her home with relieved pain.

\section{Patient four - our first patient with the ASR procedure:}

The 44-year-old male had a motorcycle accident, and the CT showed that he had suffered an AndersonD'Alonso type II. odontoid fracture, during which a $17 \mathrm{~mm}$ long cortical bone fragment from the process 
broke off and punctured the dura while causing compression to the medulla oblongata. The MRI scan confirmed liquor-leakage behind the odontoid process and showed injury to the posterior ligamentous complex. The patient was tetraplegic on admission. At the first step, we performed an emergency C1-2 fusion and the removal of the posterior arch of the $\mathrm{C} 1$ vertebra to decompress the medulla oblongata. Due to the patient's instable circulatory system we could not perform the ventral decompressive surgery immediately, but only 7 days later. During this ASR procedure we removed the middle third of the odontoid process, as well as the haematoma and the cortical bone fragment causing the compression. In the course of the operation we also explored the dural injury, and successfully tamponaded and tissueglued it. The patient is now self-sufficient.

The mean operative time in the cases was 145 minutes. Tracheostomy was not needed in any of the cases. The patients were extubated immediately after the procedure. They spent 12 hours in the intensive care unit for observation and were started on an oral diet within 24 hours. There were no intra- or postoperative complications, and significant neurological improvement presented in every case. The mean follow-up time was 8.25 months $(15,8,4,6)$. The 83 -year-old male operated due to the rheumatoid pannus died four months after the surgery in Clostridium difficile sepsis. The other three patients are alive, able to walk and are self-sufficient. During the four surgeries - on average - we operated $94.3 \mathrm{~mm}$ deep, measured from the skin incision. This was calculated by averaging the distance measured from the skin surface to the $\mathrm{C} 1$ tubercle, the ventral surface of the $\mathrm{C} 2$ and the deepest point of the freed-up dura in all four cases (altogether 12 values). The area of decompression measured in the coronal plane was 5.44, $4.84,4.83$ and $3.50 \mathrm{~cm}^{2}-4.65 \mathrm{~cm}^{2}$ in average. We planned the surgeries with the TO method using CT scans. In these cases, the mean length of the surgical channel would have been $89.8 \mathrm{~mm}-4.5 \mathrm{~mm}$ less than with the MIS ASR. The maximum possible area of decompression, measured in the coronal plane on the CT scans, would have been 7.35, 5.81, 5.61 and $5.44 \mathrm{~cm}^{2}-6.05 \mathrm{~cm}^{2}$ in average. Based on our calculations, we assume that by using the TO approach, we could have decompressed a larger dural surface by an average of $1.40 \mathrm{~cm}^{2}$. We believe that this difference occurs due to the fact that during the MIS ASR surgery - compared to the TO method - the distance between the $\mathrm{C} 1$ anterior tubercle and the midline of the corpus of $\mathrm{C} 2$ is seen at a more obtuse angle, reducing the possible area of decompression by $1.40 \mathrm{~cm}^{2}$ (Figure 3).

\section{Discussion}

The most common complications associated with transoral and transnasal odontoidectomy are CSF leakage, velopharyngeal insufficiency, wound dehiscence, pulmonary issues, meningitis and death [13]. In a systematic review, after analyzing 26 publications, Shriver et al found that the only statistically significant difference between the complication rates of the two methods was the increased incidence of tracheostomy after transoral surgeries $[13,14]$. Although the lateral routes provide a wider access, the risks of vertebral artery, jugular bulb and hypoglossal nerve injuries are higher [8-11]. Ponce-Gómez et al found a significant difference between the time duration of the TO and EE approaches. TO surgeries lasted 141 minutes in average, while the EE-s lasted 238 minutes, $p \leq 0.02$. Patients, who received the EE 
procedure, could be extubated immediately after the surgery, while patients who underwent the TO method stayed intubated for 24 hours. Time until oral feeding was significantly shorter in the EE group, $p$ $\leq 0.009$ [15].

\section{Conclusions}

The anterior submandibular retropharyngeal key-hole approach we used is a novel, minimally invasive method for the decompression of C1, C2 ventral pathologies. From the four presented cases, we cannot come to long term conclusions, but we can state that during the MIS ASR - with the preservation of the hard and soft palates - the risk of velopharyngeal insufficiency associated with the TO method can be eliminated, as well as the risk of liquor-leakage. The blood-loss is minimal, the patients do not need tracheostomy, and can be started on oral diet within 24 hours after surgery. The MIS ASR, compared to the TO method, provided on average $23 \%\left(4.56 \mathrm{~cm}^{2} / 6.05 \mathrm{~cm}^{2}\right)$ smaller dural decompression area; nonetheless, the entire pathology could be removed in all cases (Fig. 4). The small - $25 \mathrm{~mm}$ wide incision, the deep surgical field ( $94.3 \mathrm{~mm}$ on average), and the narrow surgical channel require proficient microsurgical skills.

\section{List Of Abbreviations}

MIS ASR - microscope assisted minimally invasive anterior submandibular retropharyngeal

TO - transoral transpharyngeal odontoidectomy

EE - endoscopic endonasal odontoidectomy

AR - anterior retropharyngeal

$\mathrm{MRI}$ - magnetic resonance imaging

CSF - cerebrospinal fluid

CT - computed tomography

\section{Declarations}

\section{Ethics approval and consent to participate:}

Ethical approval was waived by the local Ethics Committee of University in view of the retrospective nature of the study and all the procedures being performed were part of the routine care.

\section{Consent for publication:}

All participant gave written consent for their clinical data to be published. We do not publish any identifying personal information or images - clinical or otherwise. 
Availability of data and materials:

All data generated or analysed during this study are included in this published article.

\section{Competing interests:}

The authors declare that they have no competing interests.

\section{Funding:}

The authors included in this study have no applicable financial relationships to disclose. Specifically, there are no study funding sources or potential conflict of interest associated biases to disclose.

\section{Authors' contributions:}

Á. V. developed and performed the surgical intervention, drafted the manuscript, and supervised the work.

I. K. assisted during the operations, collected and processed the necessary data and patient documentation.

D. S. assisted during the operation, collected and processed the necessary data and patient documentation and contributed to the final form of the manuscript.

Each author has approved the submitted version and hold themselves accountable for the author's own contributions and ensure that the accuracy and integrity of any work are appropriately investigated, resolved and documented.

\section{Acknowledgements:}

Not applicable

\section{References}

1. lacoangeli M, Di Rienzo A, Colasanti R, Re M, Nasi D, Nocchi N, et al. Endoscopic Transnasal Odontoidectomy With Anterior C1 Arch Preservation and Anterior Vertebral Column Reconstruction in Patients With Irreducible Bulbomedullary Compression by Complex Craniovertebral Junction Abnormalities: Operative Nuance. Operative neurosurgery. 2016;12(3):222-30.

2. Ishida W, McCormick KL, Lo S-fL. Craniocervical Approach: Transcervical. In: Sciubba DM, editor. Spinal Tumor Surgery. Cham: Springer International Publishing; 2019. p. 29-41.

3. Yu Y, Hu F, Zhang X, Sun C. Endoscopic Transnasal Odontoidectomy. Sports medicine and arthroscopy review. 2016;24(1):2-6.

4. Zoli M, Mazzatenta D, Valluzzi A, Mascari C, Pasquini E, Frank G. Endoscopic Endonasal Odontoidectomy. Neurosurgery clinics of North America. 2015;26(3):427-36. 
5. lacoangeli M, Gladi M, Alvaro L, Di Rienzo A, Specchia N, Scerrati M. Endoscopic endonasal odontoidectomy with anterior $\mathrm{C} 1$ arch preservation in elderly patients affected by rheumatoid arthritis. Spine J. 2013;13(5):542-8.

6. Hodges SD, Humphreys SC, Brown TW, Jr., Eck JC, Covington LA. Complications of the anterior retropharyngeal approach in cervical spine surgery: a technique and outcomes review. Journal of the Southern Orthopaedic Association. 2000;9(3):169-74.

7. Srivastava SK, Aggarwal RA, Nemade PS, Bhosale SK. Single-stage anterior release and posterior instrumented fusion for irreducible atlantoaxial dislocation with basilar invagination. Spine J. 2016;16(1):1-9.

8. al-Mefty O, Borba LA, Aoki N, Angtuaco E, Pait TG. The transcondylar approach to extradural nonneoplastic lesions of the craniovertebral junction. J Neurosurg. 1996;84(1):1-6.

9. Stevenson GC, Stoney RJ, Perkins RK, Adams JE. A transcervical transclival approach to the ventral surface of the brain stem for removal of a clivus chordoma. J Neurosurg. 1966;24(2):544-51.

10. Perrini P, Benedetto N, Guidi E, Di Lorenzo N. Transoral approach and its superior extensions to the craniovertebral junction malformations: surgical strategies and results. Neurosurgery. 2009;64(5 Suppl 2):331-42; discussion 42.

11. Ture U, Pamir MN. Extreme lateral-transatlas approach for resection of the dens of the axis. $\mathrm{J}$ Neurosurg. 2002;96(1 Suppl):73-82.

12. Suvegh D, Viola A. Microscope-assisted odontoid resection via submandibular retropharyngeal "keyhole" approach. Orv Hetil. 2020;161(31):1302-6.

13. Tubbs RS, Demerdash A, Rizk E, Chapman JR, Oskouian RJ. Complications of transoral and transnasal odontoidectomy: a comprehensive review. Childs Nerv Syst. 2016;32(1):55-9.

14. Shriver MF, Kshettry VR, Sindwani R, Woodard T, Benzel EC, Recinos PF. Transoral and transnasal odontoidectomy complications: A systematic review and meta-analysis. Clinical neurology and neurosurgery. 2016;148:121-9.

15. Ponce-Gomez JA, Ortega-Porcayo LA, Soriano-Baron HE, Sotomayor-Gonzalez A, Arriada-Mendicoa $\mathrm{N}$, Gomez-Amador JL, et al. Evolution from microscopic transoral to endoscopic endonasal odontoidectomy. Neurosurg Focus. 2014;37(4):E15.

\section{Table}


Table 1

The length of the surgical channel with the MIS ASR and the TO method

\begin{tabular}{|c|c|c|c|c|c|c|c|c|}
\hline \multirow[t]{3}{*}{ No. of patient } & \multicolumn{4}{|c|}{ MIS ASR } & \multicolumn{2}{|c|}{ TO } & \multirow{3}{*}{$\begin{array}{l}\text { O-D/ } \\
\mathrm{mm}\end{array}$} & \multirow{3}{*}{$\begin{array}{l}\mathrm{DF} / \\
\mathrm{cm}^{2}\end{array}$} \\
\hline & I-C1/ & I-C2/ & I-D/ & DF/ & O-C1/ & $\mathrm{O}-\mathrm{C} 2 /$ & & \\
\hline & $\mathrm{mm}$ & $\mathrm{mm}$ & $\mathrm{mm}$ & $\mathrm{cm}^{2}$ & $\mathrm{~mm}$ & $\mathrm{~mm}$ & & \\
\hline 1. & 105 & 91 & 128 & 3.50 & 76 & 85 & 98 & 5.81 \\
\hline 2. & 98 & 79 & 110 & 4.83 & 89 & 96 & 111 & 7.35 \\
\hline 3. & 95 & 74 & 102 & 5.44 & 77 & 93 & 101 & 5.44 \\
\hline 4. & 78 & 70 & 101 & 4.84 & 74 & 86 & 91 & 5.61 \\
\hline
\end{tabular}

MIS ASR - minimally invasive anterior submandibular retropharyngeal key-hole approach

TO - transoral approach

I-C1 - distance between the incision and C1 vertebra's anterior tubercle

I-C2 - distance between the incision and the ventral base of $\mathrm{C} 2$ vertebra

I-D - distance between the incision and the deepest point of the dura mater

DF - decompressed dura mater surface

0-C1 - distance between the orifice and C1 vertebra's anterior tubercle

0-C2 - distance between the orifice and the ventral base of C2 vertebra

O-D - distance between the orifice and the deepest point of the dura mater

\section{Figures}




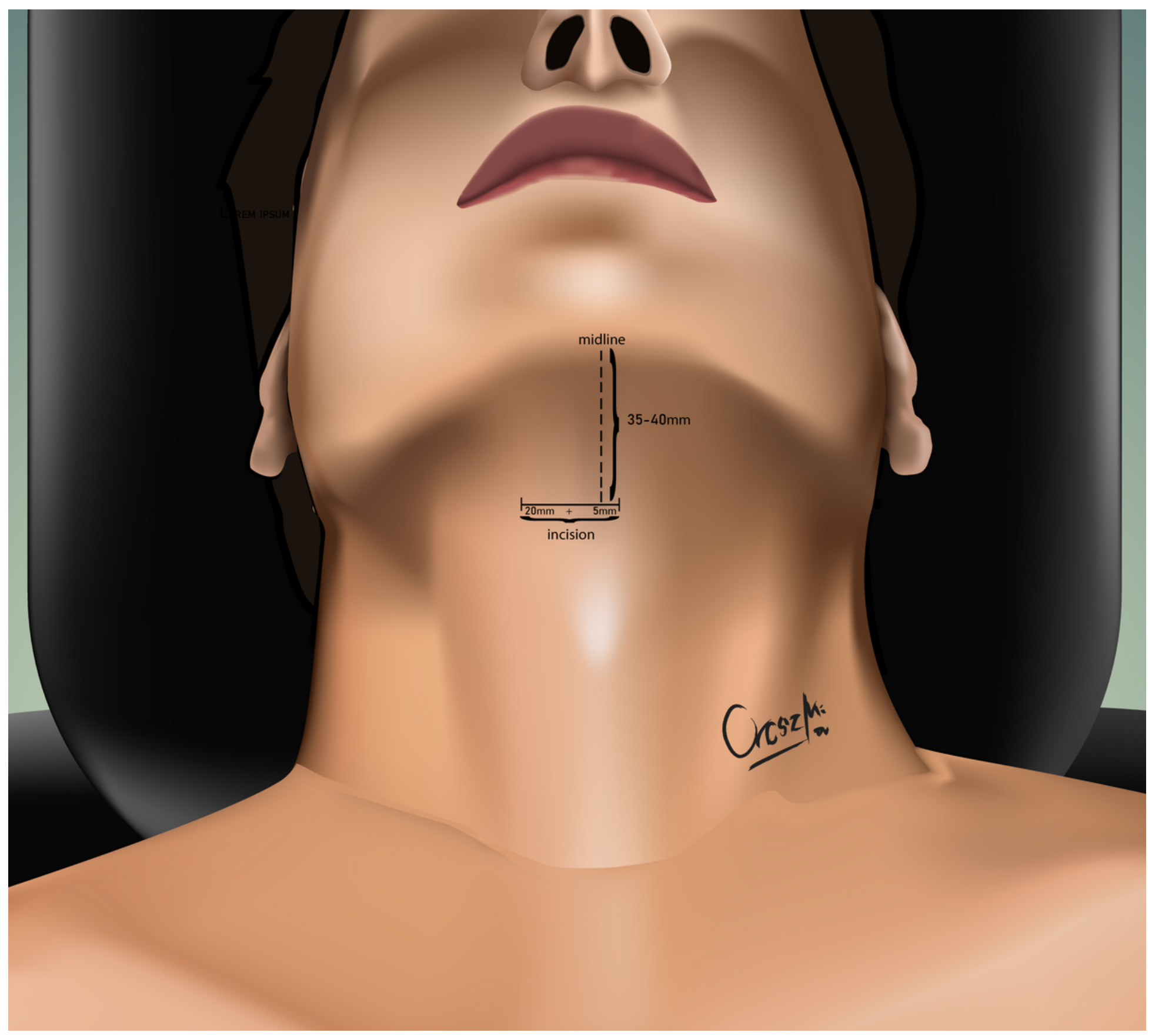

Figure 1

Location of skin incision 


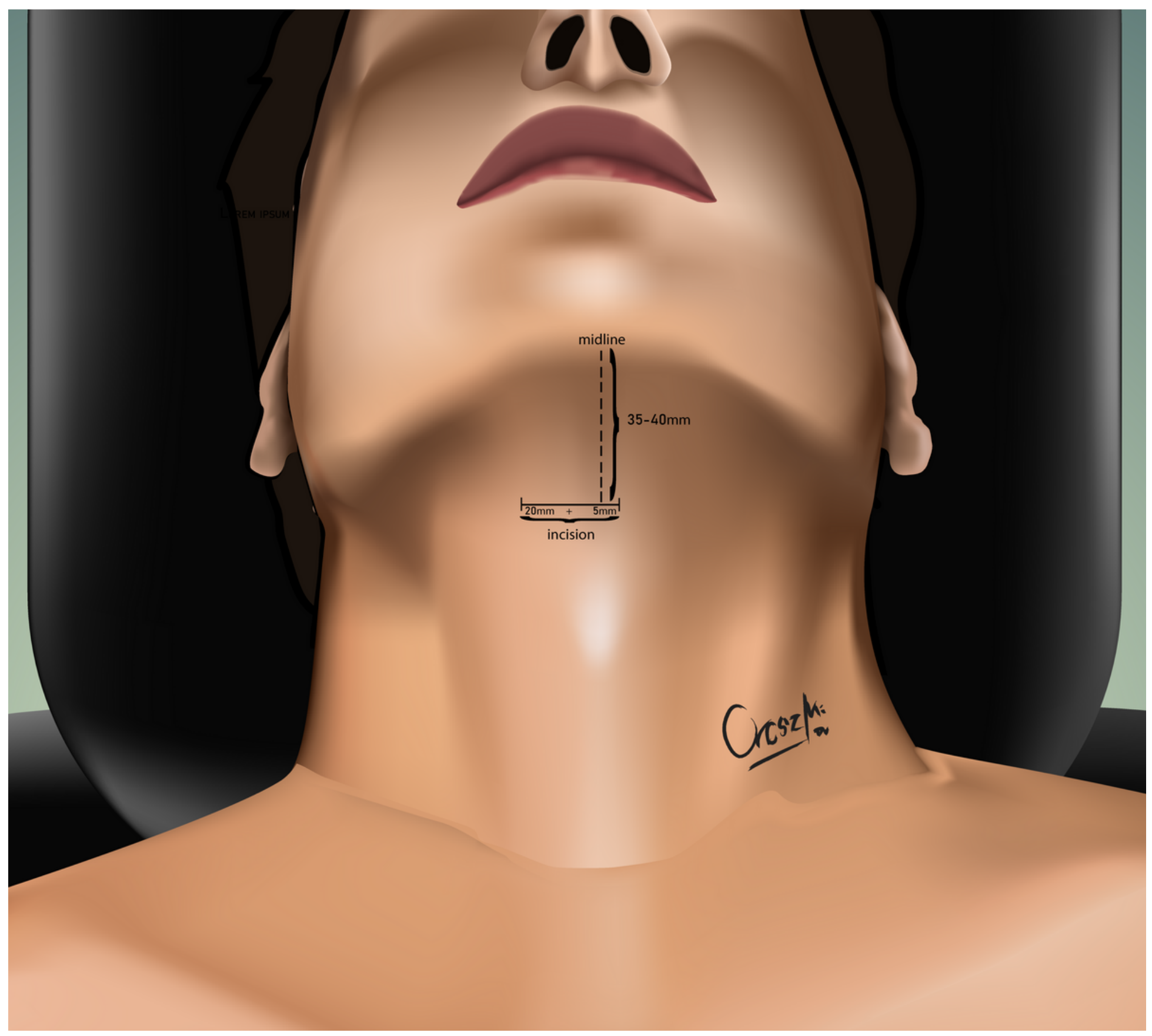

Figure 1

Location of skin incision 


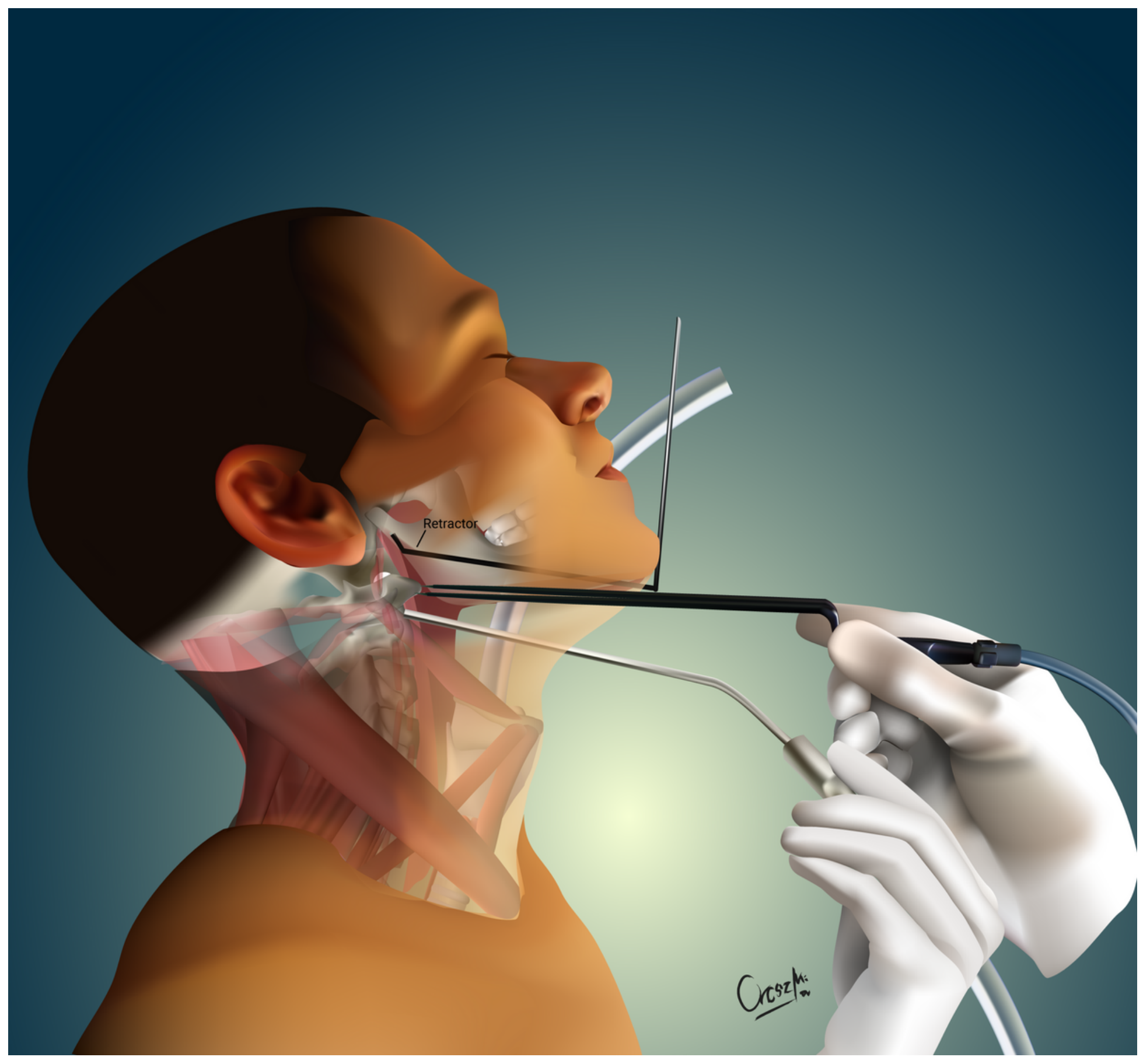

Figure 2

Mobilization of oropharynx with retractor and retraction of soft tissue with bipolar diathermy and suction 


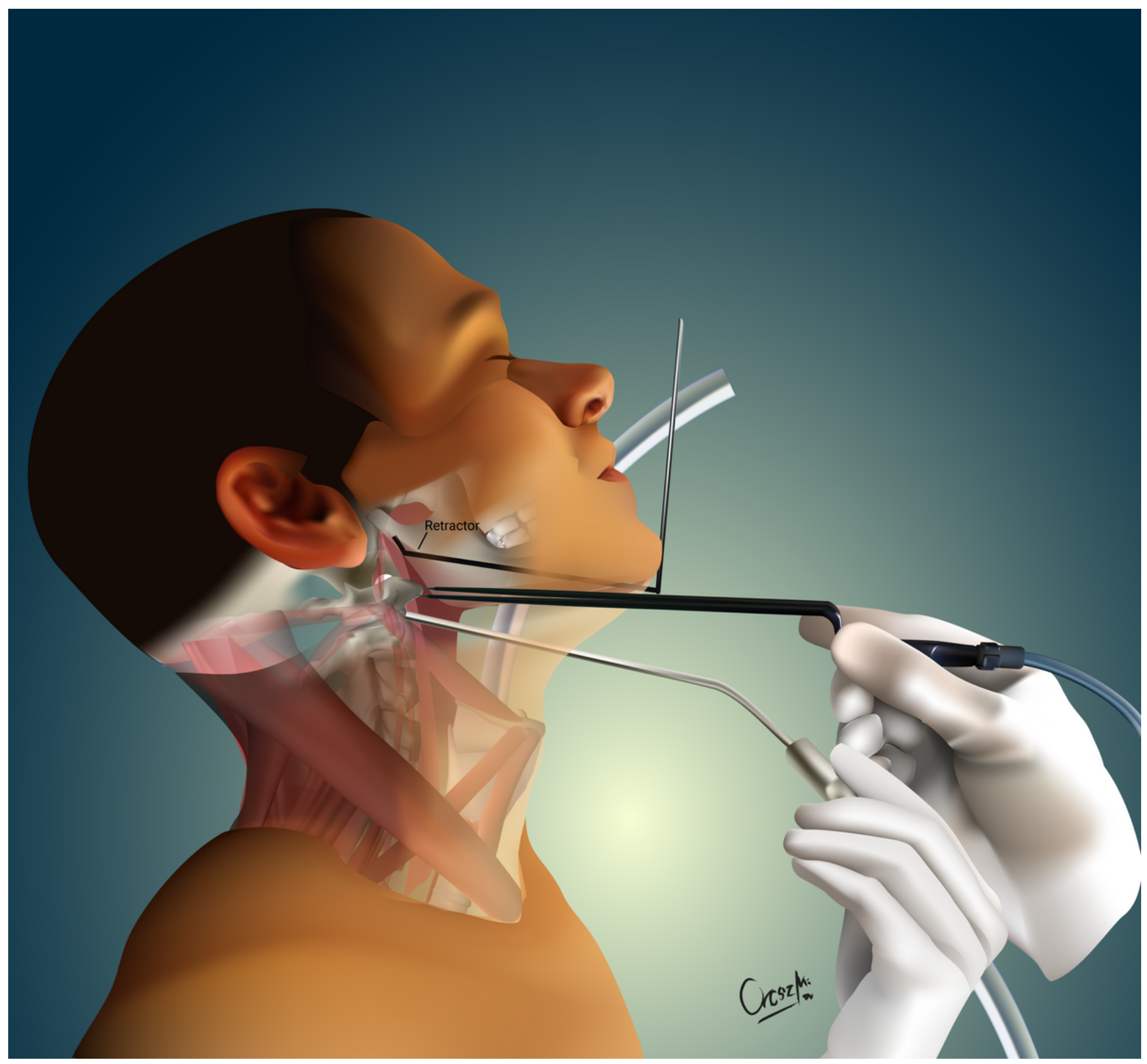

Figure 2

Mobilization of oropharynx with retractor and retraction of soft tissue with bipolar diathermy and suction 


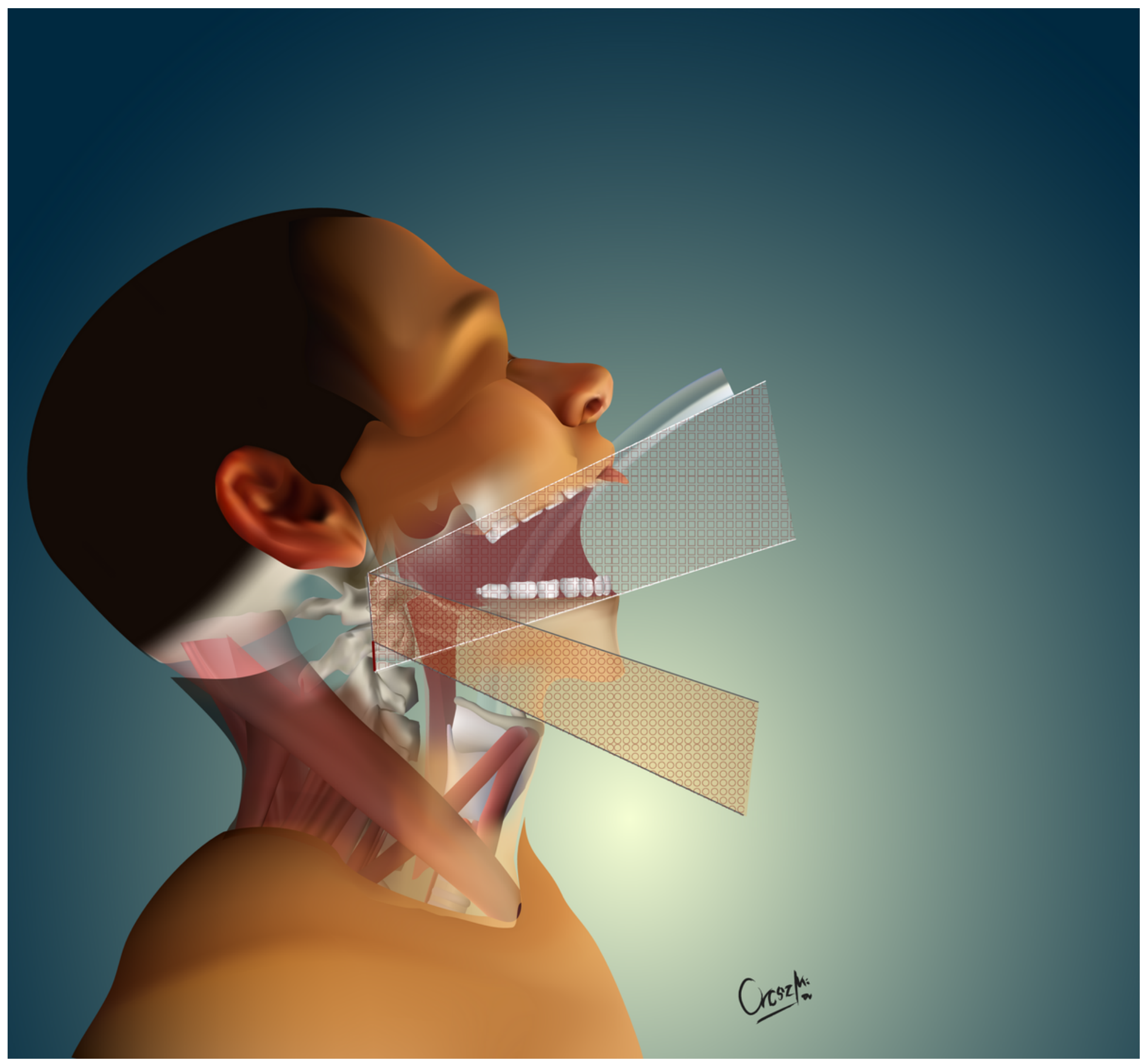

\section{Figure 3}

Schematic figure of different surgical interventions Legend: white line: maximum decompression area with the transoral method, black line: maximum decompression area with the anterior submandibular retropharyngeal method, red line: the difference between the two methods' decompression area 


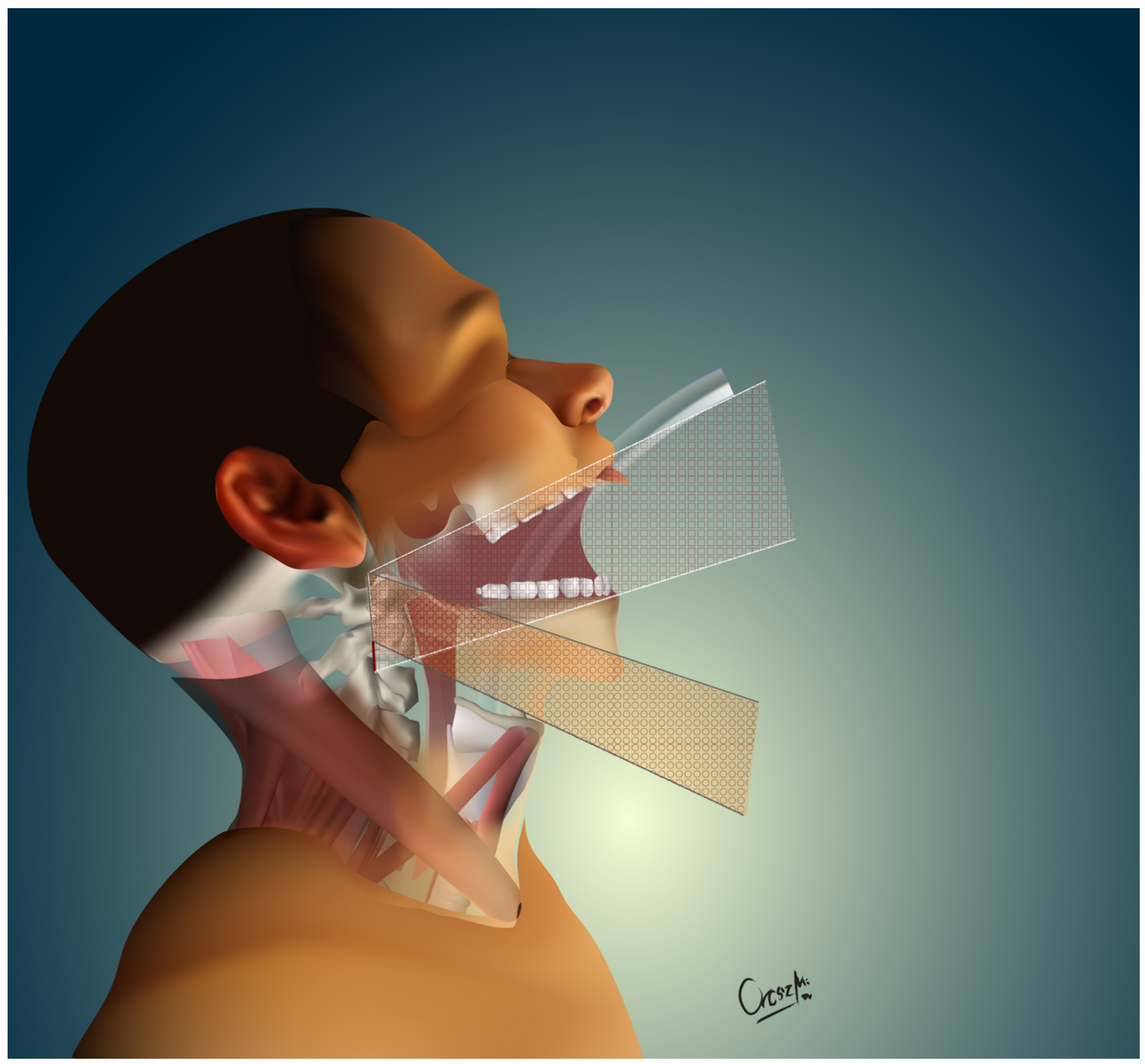

\section{Figure 3}

Schematic figure of different surgical interventions Legend: white line: maximum decompression area with the transoral method, black line: maximum decompression area with the anterior submandibular retropharyngeal method, red line: the difference between the two methods' decompression area 


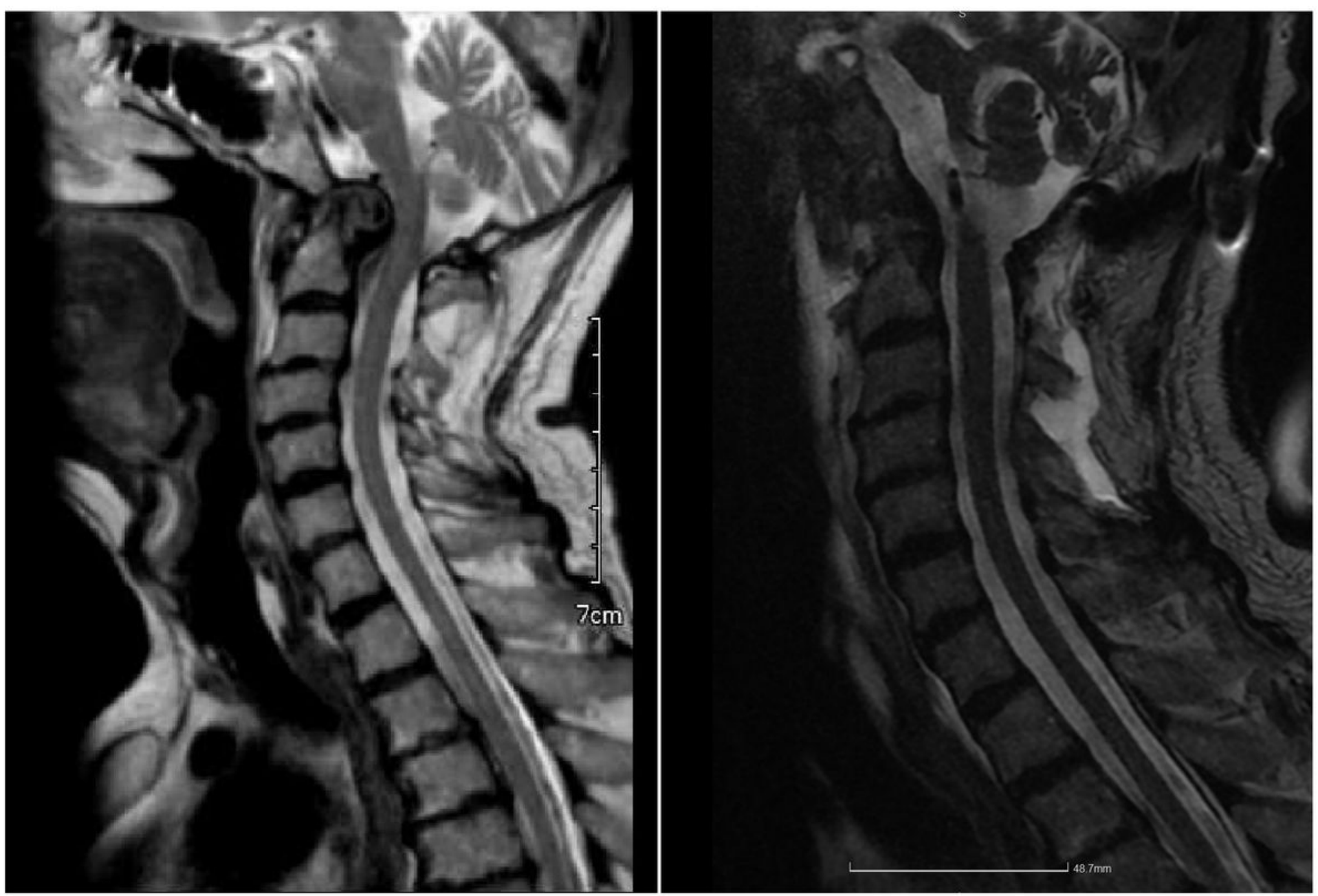

Figure 4

The preoperative (left) and postoperative (right) magnetic resonance imaging of the 62-year-old male patient 


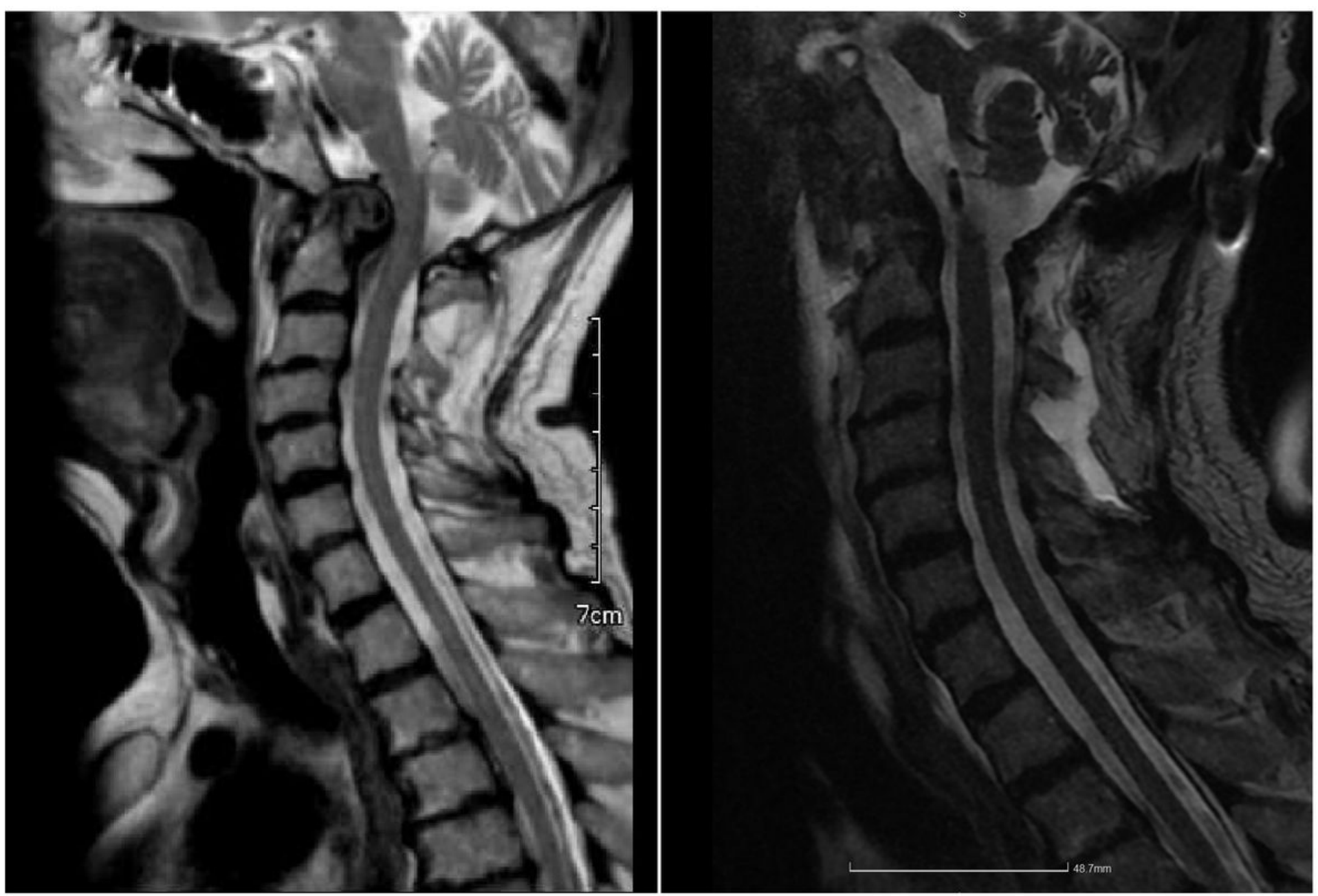

\section{Figure 4}

The preoperative (left) and postoperative (right) magnetic resonance imaging of the 62-year-old male patient

\section{Supplementary Files}

This is a list of supplementary files associated with this preprint. Click to download.

- Additionalfile1.mp4

- Additionalfile1.mp4 